\title{
Development of a Coupling Approach between OD D.I. Diesel Combustion and Pollutant Models: Application to a Transient Engine Evolution
}

\author{
F.-A. Lafossas, M. Marbaix and P. Menegazzi \\ Institut français du pétrole, IFP, Direction Techniques d'Applications Énergétiques, 1-4 avenue de Bois-Préau, 92852 Rueil-Malmaison Cedex - France \\ e-mail: f-alexandre.lafossas@ifp.fr - michaelmarbaix@gmail.com - pascal.menegazzi@ifp.fr
}

\begin{abstract}
Résumé - Modélisation 0D des émissions polluantes Diesel : développement et utilisation d'une méthodologie de couplage entre un modèle de combustion Diesel 0D et un modèle de polluants Afin de satisfaire les normes de pollution de plus en plus sévères, les constructeurs automobiles ont généralisé l'utilisation du contrôle électronique du moteur. Ce contrôle permet de s'assurer en permanence du fonctionnement optimum du moteur en adéquation avec la demande de couple du conducteur et le bon fonctionnement des organes de post-traitement. Le développement et la calibration des algorithmes de contrôle moteur ne peuvent se faire qu'avec une compréhension fine du comportement dynamique du groupe motopropulseur, couplé à sa ligne d'échappement. Jusqu'à présent, un grand nombre d'essais sur banc moteur et sur véhicule était nécessaire pour atteindre des niveaux de calibration suffisants pour le contrôleur. Afin de diminuer les coûts de production, il devient de plus en plus important de limiter ces essais expérimentaux en ayant recours à la simulation. Dans ce contexte, il est important de disposer de modèles de combustion et de polluants prédictifs, calibrés sur un nombre limité de points expérimentaux et utilisables sur une grande plage de points de fonctionnement moteur.

Ce papier présente un modèle 0D de combustion Diesel, basé sur le modèle de Barba [Barba C. et al. (2000) - A Phenomenological Combustion Model for Heat Release Rate Prediction in High Speed DI Diesel Engines with Common Rail Injection, SAE Technical Paper 2000-01-2933], permettant en particulier de prendre en compte l'impact de la multi-injection sur le déroulement de la combustion. Le modèle répartit chaque injection en deux zones : une première pour la flamme de pré-mélange lors du début de la combustion et une autre pour la flamme de diffusion. Afin de simuler la production de polluants, un modèle de mélange indexé sur l'énergie cinétique turbulente générée par le spray a été introduit. Ce dernier modèle permet de créer une zone de gaz brûlés dans la chambre de combustion dans laquelle les émissions de $\mathrm{CO}, \mathrm{NO}_{\mathrm{x}}$ et suies sont calculées. Les modèles de polluants sont d'abord validés en utilisant le logiciel CHEMKIN et des résultats de calculs 3D. Des résultats expérimentaux obtenus sur un moteur 4 cylindres Diesel à injection directe en fonctionnement stabilisé sont ensuite utilisés pour valider et calibrer le couplage entre le modèle de combustion et les modèles de polluants. Le simulateur ainsi calibré est enfin utilisé pour simuler un fonctionnement en transitoire de charge du moteur.
\end{abstract}

\footnotetext{
Abstract - Development of a Coupling Approach between OD D.I. Diesel Combustion and Pollutant Models: Application to a Transient Engine Evolution - The constant increase in pollutant emissions constraints has obliged automotive manufacturers to adopt a global optimization approach of engine and exhaust after-treatment technology. Engine control strategies appear to be a powerful solution to address this issue. The problem is particularly complex since acceptable drivability must be maintained whilst at the same time reducing in-cylinder pollutant emissions and ensuring optimum conditions to attain high
} 
conversion efficiencies via exhaust gas after-treatment systems. The development of appropriate control strategies can only be achieved with an in-depth understanding of the engine behaviour, using experimental results and system numerical simulations. In this context, predictive combustion and pollutant emissions models, which are calibrated with experimental data, are particularly useful as they allow a wide range of parametric variations to be studied.

This paper presents an advanced Diesel combustion model based on a Barba's approach [Barba C. et al. (2000)- A Phenomenological Combustion Model for Heat Release Rate Prediction in High Speed DI Diesel Engines with Common Rail Injection, SAE Technical Paper 2000-01-2933]. This model can be applied to multi-injection, defining a pre-mixed combustion zone for the pilot injection and a diffusion combustion mode for the main injection. To assess the in-cylinder pollutant emissions, a mixing model based on the turbulent kinetic energy generated by the spray, is added to define a burnt gas zone in which post-flame chemistry including $\mathrm{CO}, \mathrm{NO}_{x}$ and soot formation can be computed. This model is first validated using CHEMKIN and $3 D$ CFD results. Then, using experimental results, a 4 cylinders D.I. Diesel engine is calibrated on steady state engine operating conditions and coupled to an engine control to predict the evolution of pollutant emissions under transient conditions.

\section{NOMENCLATURE}

$\Phi$ Fuel/Air equivalence ratio

$\varepsilon \quad$ Dissipate kinetic energy

$\theta \quad$ Auto-ignition delay

$\rho \quad$ Density

$\tau \quad$ Characteristic mixing time

A Surface

d Diameter

K Kinetic constant

$\mathrm{k} \quad$ Turbulent kinetic energy

$l_{1} \quad$ Turbulent mixing length

m Mass

$\mathrm{n}_{\mathrm{N}} \quad$ Number of injector holes

$p$ Pressure bar

$T$ Temperature $\quad \mathrm{K}$

$V$ Volume $\mathrm{m}^{3}$

$v$ Speed $\mathrm{m} / \mathrm{s}$

$X \quad$ Molar fraction

$x \quad$ Number of carbon atoms of the fuel

$y \quad$ Number of hydrogen atoms of the fuel

\section{SUBSCRIPTS}

$\begin{array}{ll}+ & \text { Forward reaction } \\ - & \text { Inverse reaction } \\ \mathrm{A} & \text { Fresh air } \\ \mathrm{bg} & \text { Burnt gases } \\ \text { chem_equil } & \text { Chemical equilibrium } \\ \text { comb } & \text { Combustion } \\ \text { cyl } & \text { Cylinder } \\ \mathrm{f} & \text { Fuel }\end{array}$

$\begin{array}{ll}\text { fg } & \text { Fresh gases } \\ \mathrm{fg} \rightarrow \text { bg } & \text { Transfer from the fresh gases to the burnt ones } \\ \mathrm{i} & \text { Specie i } \\ \text { inj } & \text { Injected } \\ \text { mix } & \text { Mixing controlled combustion zone } \\ \text { NO } & \text { NO formation } \\ \text { pist } & \text { Piston } \\ \text { pre } & \text { Premixed zone } \\ \text { R } & \text { Residual burnt gases }\end{array}$

\section{ABBREVIATIONS}

CFD Computational Fluid Dynamics

CPU Central Processing Unit

DI Direct Injection

EVO Exhaust Valves Opening

IMEP Indicated Mean Effective Pressure (bar)

IVC Intake Valves Closure

$\mathrm{NADI}^{\mathrm{TM}} \quad$ Narrow Angle Direct Injection

ppm Parts per million

Re Reynold's number

RPM Revolutions Per Minute

SOI Start Of Injection

\section{INTRODUCTION}

The strict environmental constraints in terms of fuel consumption and pollutant emissions involve a global vehicle optimization. This is a real challenge that implies the management of complex interacting dynamic systems. In this context, the use of the engine control system appears to be a powerful tool to manage the different elements of 
the powertrain. In a standard Direct Injection (D.I.) Diesel engine, the engine control system has to manage at the same time a lot of actuators: injection pressure and timing, the number of injections; the turbine waste-gate position, the after-treatment regeneration. All of these actuators have to match the user request and also the pollutant emissions limits.

Thus, the development of the engine control system is more and more critical in the powertrain development loop. The use of simulation platforms in order to limit the cost and time devoted to this task is more and more present in car manufacturer's teams. The use of simulation tools appears at different steps of the engine control system development: from the understanding of the physical behaviour of the entire engine at the beginning of the loop, to the pre-calibration of the control before its introduction in the real vehicle. For these different applications, the balance accuracy/CPU cost of the models is not the same. In order to simplify and unify the tools to help the engine control development, IFP is developing an engine library in the AMESim platform [2]. This library can either be used with phenomenological models for the engine physical understanding, or with real-time facilities for engine control pre-calibration.

The reduction of pollutant emissions in D.I. Diesel applications is a general purpose, which can not be solved exclusively with the use of an exhaust post-treatment. The interaction between the in-cylinder conditions and the catalyst behaviour must be taken into account during the engine development loop. In this paper, using the IFP-Engine library, the development and the validation of a 0D Diesel combustion model is presented. This combustion model must be predictive for a wide range of applications, but its use in the engine control development loop leads to a reduction of its CPU cost. As this model has to be connected with the exhaust line, it has to be able to compute in a first time the $\mathrm{CO}$ and $\mathrm{NO}_{\mathrm{x}}$ emissions.

First, the different $0 \mathrm{D}$ combustion model approaches will be presented with their capacity to be used in our application. The chosen model is then described and implemented in the IFP-Engine library with adaptations to compute the combustion heat release rate. The development of the pollutant formation models is discussed and validated using CHEMKIN results. Finally, the developed approach is tested and validated using experimental results for a wide range of steady state operating points. The use of this approach to validate the behaviour of an entire engine on a transient evolution is presented.

\section{DIESEL COMBUSTION MODEL OVERVIEW}

The main purpose of this section is not to present an exhaustive overview of all the approaches available in the literature. We prefer to present the different combustion model "families". Different types of models can be used to simulate the Diesel combustion process. Depending on their complexity and required CPU time, these models can either be based on a multi-dimensional CFD [3, 4] or a 0D/1D systems approaches. For engine control development, a compromise between the computational speed and accuracy of the model is required, which prevents the use of multi-dimensional CFD models. The 0D/1D Diesel combustion models can be divided into 3 different groups, depending on the predictivity and computational speed:

- On one hand, there are the empirical models where the evolution of the combustion heat release rate is defined using a mathematical function as the standard simple or double Wiebe equation [5]. Generally, due to their simplicity, these models are used for real-time applications. Cesario et al. [6] defined a mathematical function to fit the combustion heat release rate. The parameters of this function were then optimized and mapped according to experimental results. Using a similar approach, Bohbot et al. [7] used a simple Wiebe law, coupled with an automatic tool to create the parameter maps using both experimental and 3D CFD results. In order to increase the accuracy of their model, Arsie et al. [8] used two different functions for the pre-mixed and diffusion combustion, coupled with a simple auto-ignition delay and $\mathrm{NO}_{\mathrm{x}}$ formation model, which induce a large number of parameters. For these models, the physical knowledge is not directly introduced in the combustion model, but much more in the parameter optimization.

- Another approach is the use of phenomenological OD models with the description of several zones (more than 2 ), depending on the description of the spray and combustion. The number of zones is defined according to phenomenological or spatial considerations. The most widely used model in this category is the Hiroyasu et al. approach [9-12]. The injected mass flow rate is divided into packets (with a constant injected mass or a constant step time), in which can be computed the spray evaporation, the mixture with fresh air, the combustion and the pollutant formation. Each pack is free from the others. If the user wants a realistic description of the combustion, the number of packs must be important, leading to an important increase of the CPU time. Another way to define the n-zones is to use phenomenological approaches. We can present the model of Asay et al. [13] which uses the Dec physical description of Diesel combustion $[14,15]$. The spray is thus divided into 5 spatial zones depending on its penetration. These $0 \mathrm{D}$ combustion models generally have a good physical behaviour. Moreover they can easily be coupled with pollutant formation models although a lot of state variables have to be defined to compute the thermodynamic behaviour of the different zones, leading to significant CPU consumption. 
- Considering the two approaches described above we can classify the phenomenological models using less than 3 zones to compute the conventional Diesel combustion. Most of the models use 2 zones: a first zone for the description of the pre-mixed combustion and a second one for the diffusion mode. In a first step, Chmela et al. [16] defined a model for the description of the mixing controlled combustion. Unfortunately, with the generalization of the pilot injection, the pre-mixed combustion mode can no longer be neglected. Several models are now available for the description of this combustion mode $[17,18]$. Chmela et al. [17] introduced its modelling in their previous model, increasing its predictability. Barba et al. [1] also developed a two zone model for the simulation of conventional Diesel combustion.

The main purpose of our paper is to define a predictive Diesel combustion model to assess the pollutant emissions, and then to introduce it in an entire engine simulation. Even if they seem promising, because of their CPU cost, the nzones models are difficult to use for these kind of applications. As presented in Reference [1], the Barba's model can reproduce the conventional Diesel combustion process, using only 2 zones. With a reduced number of parameters, it can be used for a wide range of operating points. Thus, we decided to use the Barba's approach to compute the combustion heat release rate. The pollutant emissions are then modelled, using pollutant formation models coupled with the combustion model.

\section{ADVANCED BARBA BASED COMBUSTION MODEL}

As discussed in the previous section, a Barba's based combustion model [1] is chosen to compute the combustion heat release rate. In this approach, the combustion process is divided in 2 steps. In a first step, the fuel is burnt using a premixed model with the hypothesis of flame propagation in the pre-mixed zone. In a second step, when the pre-mixed zone is burnt, the remaining fuel is oxidized using a mixing controlled combustion model. The different hypothesis and equations of the Barba's combustion model are presented in Reference [1]. In this section, the main equations will be presented using Figure 1 to describe the behaviour of the combustion model.

Using a simple example with a pilot and main injection, 7 different steps, presented with surrounded numbers in Figure 1, can be isolated during the combustion. Figure 1 presents the evolution of the main variable of the combustion model: the injected mass flow rate, with the 2 injections, the evolution of the auto-ignition delay (when it reaches 1 , the combustion can start), the repartition of the injected fuel in the pre-mixed zone and the combustion heat release rate. The curves in solid lines are connected with the pilot injection, whereas the dotted lines represent

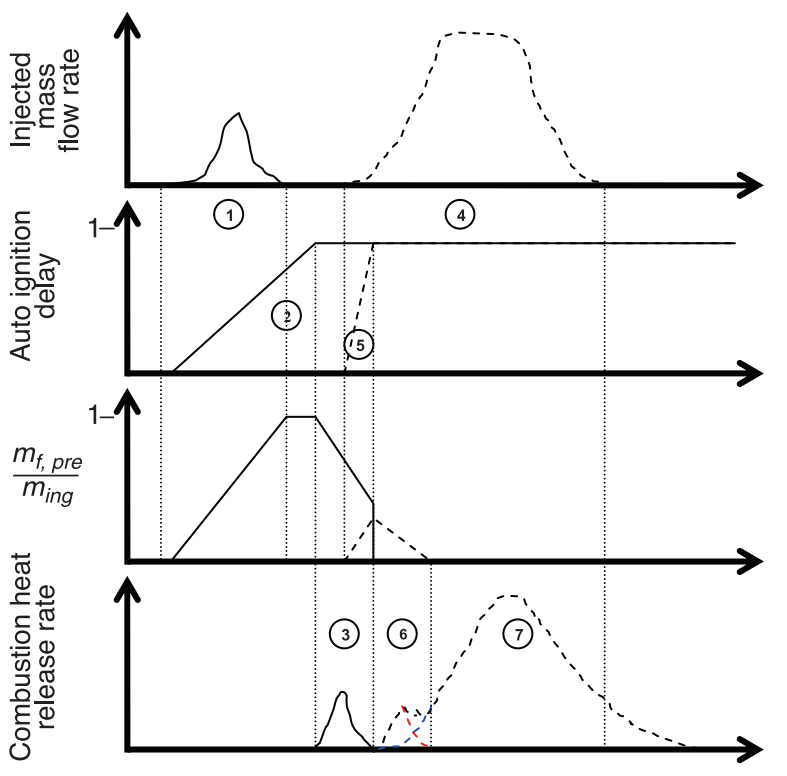

Figure 1

Barba based combustion model behaviour

the main injection. The 7 different steps will be presented successively in the following paragraphs.

\subsection{Pilot Injection}

At the beginning of the pilot injection, the combustion model is initialized and the different variables are computed. During injection, the auto-ignition delay is computed and the injected fuel is introduced in the pre-mixed zone. In our case, the auto-ignition delay is reached after the end of the injection, thus all the injected fuel is located in the pre-mixed zone.

\subsubsection{Auto-ignition Delay for the Pilot Injection}

The auto-ignition delay $\theta_{0}$ is defined at the beginning of the injection. In 0D Diesel combustion models, the auto-ignition delay is generally defined with one step chemistry $[1,19]$. These relatively simple models can be used for conventional Diesel combustion in which the evolution of the logarithm of the auto-ignition delay is relatively proportional to the inverse of the temperature. The auto-ignition delay $\theta_{0}$ is thus computed using a simple Arrhenius law:

$$
\theta_{0}=A_{t} \cdot p^{-n} \cdot e^{\frac{T_{A}}{T}}
$$

where, $A_{t}, n$ and $T_{A}$ are the auto-ignition delay parameters, $p$ and $T$ are the pressure (bar) and the temperature $(\mathrm{K})$ in the combustion chamber respectively. To take into account the effects of burnt gases on the auto-ignition delay, compared 
with the standard Barba combustion model, the delay $\theta_{0}$ is modified according to the burnt gases molecular fraction $X_{b g}$ :

$$
\theta=\frac{\theta_{0}}{1+\gamma \cdot X_{b g}}
$$

where $\gamma$ is a parameter to be defined. The different parameters defined in the correlations are fitted using experimental results. The inverse of this delay is then integrated from the Start Of the Injection (SOI), and when the integral reaches 1, the combustion starts:

$$
\int_{S O I} \frac{1}{\theta}=1
$$

The use of a simple auto-ignition delay model was done to achieve a Diesel combustion model useful for engine control definition under conventional operating points. In parallel to this development, the influence of the mixture preparation on the distribution of the Fuel/Air equivalence ratio, and the complex chemistry for the low temperature combustions are investigated [20].

\subsubsection{Pilot Injection Combustion}

When the auto-ignition delay is reached, the pre-mixed combustion starts, leading to consumption of the premixed fuel. The evolution of the pre-mixed zone is summarized in Figure 2.

The pre-mixed zone is always created at the beginning of injection. During the injection and if the auto-ignition delay is not reached, which is the case of Figure 1, the

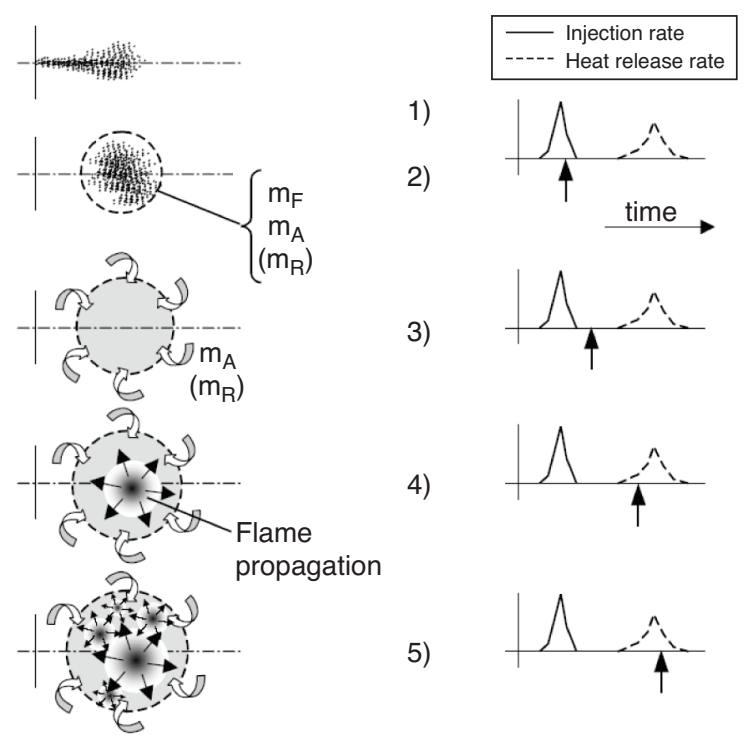

Figure 2

Evolution of the pre-mixed zone (from [1]). injected fuel mass is introduced in the pre-mixed zone. The fresh air and the burnt gases are also entrained in this zone using the equation:

$$
\frac{d\left(m_{f g}+m_{b g}\right)_{p r e}}{d t}=\Lambda \cdot \frac{d m_{f, i n j}}{d t}
$$

where $\Lambda$ is a parameter defined to maintain the Fuel/Air equivalence ratio to 1.25 , in the case of no residual burnt gases. If the auto-ignition delay is not reached at the end of the injection, the pre-mixed zone grows because of the diffusion of the fuel in the surrounding gas. As presented in [1], the diffusion of the fuel out of the pre-mixed zone is defined by Equation 5 . In this equation, $\rho_{f, p r e} / d_{\text {pre }}$ is the density of the fuel in the pre-mixed zone, divided by its diameter (with the hypothesis of a spherical zone).

$$
\frac{d m_{f, p r e}}{d t}=c \cdot D \cdot \sqrt{\operatorname{Re}} \cdot A_{p r e} \cdot \frac{\rho_{f, p r e}}{d_{p r e}}
$$

$A_{\text {pre }}$ is the surface of the pre-mixed zone; Re is the Reynolds number, calculated with a velocity proportional to the mean piston velocity and a length approximated as $V_{c y l}^{1 / 3}$. c.D is a constant equal to $1.0 \mathrm{e}-4 \mathrm{~m}^{2} / \mathrm{s}$. As the approach assumes that the fuel remains in the pre-mixed zone, the diffused mass of the fuel calculated using Equation 5 will be used to define the entrained mass of fresh air and residual burnt gas. This entrained gas model leads to a reduction of the Fuel/Air equivalence ratio in the pre-mixed zone.

When the auto-ignition delay is reached at the end of the part 2, the pre-mixed combustion starts. The combustion of this zone is then divided into two main processes, as presented in Figure 3.

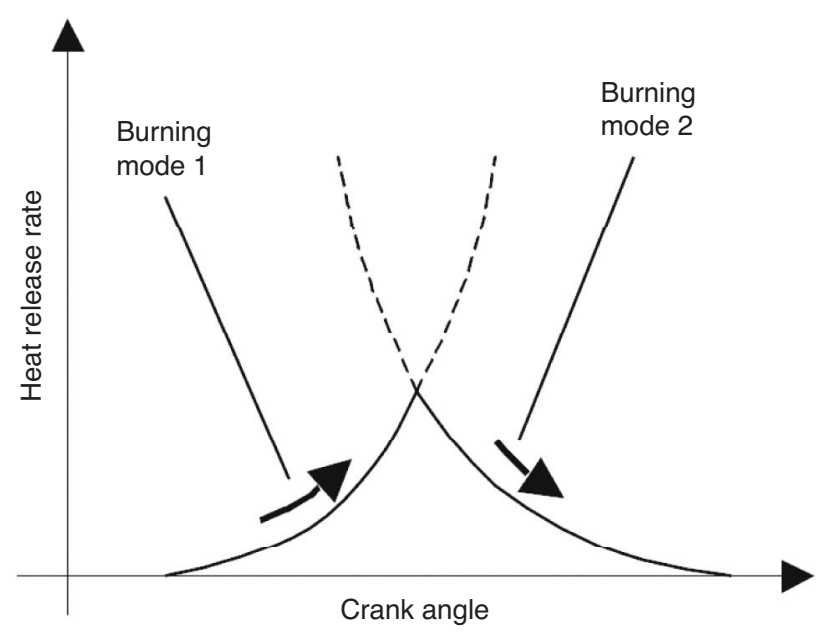

Figure 3

Pre-mixed combustion model (from [1]). 
In a first step, the ascendant part of the combustion heat release rate (burning mode 1) is generated by the flame propagation in a turbulent field. The equations to compute the burning rate are defined in the Barba et al. paper [1], and are similar to the equations presented in $[3,19]$ for the propagation of a flame in an homogeneous mixture. Then, because of the multiplication of the auto-ignition site, the hypothesis of the propagation of a single flame in the pre-mixed zone is no more valid and the flame interactions have to be modelled (burning mode 2), leading to a reduction of the total flame surface. The 2 burning modes for the pilot injection are represented in Figure 3.

\subsection{Main Injection}

When the main injection starts, the combustion of the first injection is not stopped. The model creates a new pre-mixed zone for the main injection and computes the auto-ignition delay. The definition of the pre-mixed zone is similar to the pilot injection one.

\subsubsection{Auto-ignition Delay for the Main Injection}

As for the first injection, the auto-ignition delay of the main injection is computed from the beginning of the injection until it reaches 1 , leading to the beginning of the combustion. The auto-ignition model is the same as for the pilot injection, but thanks to a higher pressure and temperature, the autoignition delay is smaller and reached before the end of the injection. The injected mass of fuel before the auto-ignition delay burns in the pre-mixed zone, whereas the remaining injected fuel will burn using a mixing controlled combustion model.

\subsubsection{Pre-mixed Combustion for the Main Injection}

As the auto-ignition delay is reached before the end of the injection, the fraction of fuel available in the pre-mixed zone is lower than for the pilot injection (see Fig. 1). The combustion process is the same than for the first injection and its combustion heat release rate is plotted with a red dotted line in the last graph of Figure 1. The pilot combustion is stopped at the start of the main combustion, visible in Figure 1. The remaining fuel in the pre-mixed zone is then considered as available fuel which is then present in the mixing controlled zone of the main combustion.

\subsubsection{Mixing Controled Combustion for the Main Injection}

In parallel to the pre-mixed combustion mode, the remaining injected fuel starts to burn progressively with a mixing controlled combustion model. In this burning mode, the combustion is piloted by the mixture speed between the injected fuel and the surrounding air. Generally, the mass of fuel burnt in this mode is defined with a simple equation [1, 16-19]:

$$
\frac{d m_{f, m i x}}{d t}=f(k) \cdot m_{f, m i x}
$$

where $m_{f, \text { mix }}$ is the available mass of fuel in the mixing controlled zone. $f(k)$ is a function of the turbulent kinetic energy in the combustion chamber, if the mixture between the injected fuel and the fresh air is supposed to be mixed by the turbulent kinetic energy $k$. According to the work of Chmela et al. [16] and Jaine [11], the turbulent kinetic energy $k$ in a DI Diesel engine is mainly created by the kinetic energy introduced by the spray. For conventional operating points, the contribution of the squish and swirl flows on the total kinetic energy can be neglected, compared with the energy introduced by the spray. The evolution of $k$ is calculated with Equation 7:

$$
\frac{d k}{d t}=-c_{\text {DISS }} \cdot \frac{1}{l_{l}} k^{\frac{3}{2}}+\left.\frac{d k}{d t}\right|_{\text {spray }}
$$

The first part of Equation 7 defines the dissipation of the turbulent kinetic energy with the parameter $c_{D I S S}$ and the integral length $l_{l}$, which is assumed to be smaller than the injector nozzle diameter. The turbulent kinetic energy created by the injected spray is defined by the second term of Equation 7. In the Barba's model, the function of the turbulent kinetic energy $f(k)$ is a frequency, defined as the quotient of a characteristic mixing velocity and a characteristic mixing length. The characteristic mixing length is a function of the combustion chamber volume $V_{c y l}$, the number of nozzle holes $n_{N}$ and the fuel/air equivalence ratio $\Phi$. The characteristic mixing velocity is a function of the mean piston velocity $v_{\text {pist }}$ and the turbulent kinetic energy $k$. Thus, the mass of fuel burnt during the mixing controlled combustion mode is computed as:

$$
\frac{d m_{f, \text { mix }}}{d t}=\frac{\sqrt{c_{p i s t} \cdot v_{p i s t}^{2}+c_{k} \cdot k}}{\sqrt[3]{\frac{\Phi \cdot V_{c y l}}{n_{N}}}} \cdot m_{f}
$$

In order to enlarge the range of applications of this combustion model, we introduce the possibility to compute a third injection and combustion. For each injection, the parameters $A_{t}, n$ and $T_{A}$ have to be defined. The other parameters of the combustion model (for the definition of the pre-mixed and mixing controlled zones) are set constant for the different injections.

\section{POLLUTANT FORMATION MODEL DESCRIPTION}

In parallel to the development of the combustion model, the possibility to introduce the simulation of the pollutant emission formation was investigated. In a first step of the development of the model, the formation of the $\mathrm{CO}$ and $\mathrm{NO}$ are discussed. The soot and unburned hydrocarbon formation 
will be studied in future work. This section is divided into two parts; the first one is dedicated to the $\mathrm{CO}$ formation, defining the different possibilities for its creation, and the second one for the NO formation.

\subsection{CO Formation and Oxydation}

The $\mathrm{CO}$ is formed during the combustion process, in the rich zones. In these zones, instead of using a conventional chemical equation for the oxidation of the fuel, we defined a correlation as a function of the fuel/air equivalence ratio $\Phi$ :

$$
\left\{\begin{array}{l}
C_{x} H_{y}+\left(x+\frac{y}{4}\right) \cdot O_{2} \rightarrow x \cdot \mathrm{CO}_{2}+\frac{y}{2} \cdot \mathrm{H}_{2} \mathrm{O}, \quad \Phi<0.98 \\
\alpha_{1} \cdot\left(C_{x} H_{y}+\left(x+\frac{y}{4}\right) \cdot O_{2} \rightarrow x \cdot \mathrm{CO}_{2}+\frac{y}{2} \cdot H_{2} O\right)+ \\
\left(1-\alpha_{1}\right) \cdot\left(C_{x} H_{y}+\frac{x}{2} \cdot O_{2} \rightarrow x \cdot C O+\frac{y}{2} H_{2}\right) \quad \Phi \geq 0.98
\end{array}\right.
$$

With the conservation of the atom number of $\mathrm{C}, \mathrm{H}$ and $\mathrm{O}$ and the fuel/air equivalence ratio $\Phi$, it is possible to define the parameters $\alpha_{1}$, as follow:

$$
\alpha_{1}=\frac{0.98 \cdot \frac{4 x+y}{\Phi}-2 x}{2 x+y}
$$

In Equation 10, if the fuel/air equivalence ratio $\Phi$ is equal to $0.98, \alpha_{1}$ is equal to 1 , and the two equations in System 9 are equivalent. Then, if $\Phi$ increases, $\alpha_{1}$ decreases and thus the amount of CO increases. The value of $\alpha_{1}$ is limited by 0 .

In addition with the formation of $\mathrm{CO}$, due to the combustion process, it is also important to take into account the chemical equilibrium in the burnt gases. The most widely used approach is to introduce this equilibrium [9, 19, 21-24] and to solve the system described in 11 .

$$
\left\{\begin{array}{l}
\mathrm{N}_{2} \Leftrightarrow 2 \cdot \mathrm{N} \\
\mathrm{O}_{2} \Leftrightarrow 2 \cdot \mathrm{O} \\
\mathrm{O}_{2}+2 \cdot \mathrm{CO} \Leftrightarrow 2 \cdot \mathrm{CO}_{2} \\
\mathrm{H}_{2} \Leftrightarrow 2 \cdot \mathrm{H} \\
\mathrm{O}_{2}+\mathrm{H}_{2} \Leftrightarrow 2 \cdot \mathrm{OH} \\
\mathrm{O}_{2}+2 \cdot \mathrm{H}_{2} \mathrm{O} \Leftrightarrow 4 \cdot \mathrm{OH}
\end{array}\right.
$$

In this system, 10 species have to be defined, using 10 equations: 6 equilibriums defined in System 11, and 4 conservation equations for $\mathrm{C}, \mathrm{O}, \mathrm{H}$ and $\mathrm{N}$. Then using a Newton method for the system inversion, the concentration of the species at the equilibrium in the burnt gases can be solved. The 0D solver uses a variable time step solver which computes the evolution of state variables (as the mass or the pressure in the cylinder). It is thus necessary to create a simple kinetic to reach the equilibrium in the burnt gases. The evolution of the species in the burnt gases, according to the equilibrium, $\left.\frac{d m_{i}}{d t}\right|_{\text {chem_equil }} ^{b g}$ are defined using a single step Equation 12:

$$
\left.\frac{d m_{i}}{d t}\right|_{\text {chem_equil }} ^{b g}=\frac{\left(\left.m_{i}\right|_{\text {chem_equil }} ^{b g}-\left.m_{i}\right|^{b g}\right)}{\tau_{\text {chem_equil }}}
$$

where $\left.m_{i}\right|_{\text {chem_equil }} ^{b g}$ is the mass in the burnt gases of the specie $i$ according to the chemical equilibrium, $\left.m_{i}\right|^{b g}$ is the current mass in the burnt gases of the specie $i$ and $\tau_{\text {chem_equil }}$ is a parameter fixed at $10^{-4} \mathrm{~s}$.

In a first step, the validation of the chemical equilibrium implemented in the combustion model is conducted with the CHEMKIN software, using the module for the thermodynamic equilibrium (EQUIL). The comparison was conducted on a homogeneous reactor, with the hypothesis of a constant volume. The initial conditions are defined in Table 1 and are representative of the ideal composition and thermodynamic conditions in the burnt gases of a standard Diesel fuel. Several initial temperatures in the reactor have been defined to follow its impact on the concentration of the main species at the equilibrium. The influence of the parameter $\tau_{\text {chem_equil }}$ was tested and it has just an impact on the time to reach the equilibrium and not on the value of the chemical equilibrium. For the engine cases, it is set at $10^{-4} \mathrm{~s}$.

TABLE 1

Initial conditions in the homogeneous reactor

\begin{tabular}{c|c}
\hline Pressure (bar) & 50.0 \\
\hline Temperature (K) & $1500-2000-3000-4000-5000$ \\
\hline$X_{\mathrm{H}_{2} \mathrm{O}}(\%)$ & 47.39 \\
\hline$X_{\mathrm{CO}_{2}}(\%)$ & 52.61 \\
\hline
\end{tabular}

where $\mathrm{X} i$ is the molar fraction of the species $i$.

Where $X_{i}$ is the molar fraction of the species $i$. The evolution of the composition of the mixture at the chemical equilibrium is grouped in Table 2 for the different initial temperatures. The relative errors between CHEMKIN and the OD Diesel combustion model are always below $3.0 \%$ for the minority species, and $1.5 \%$ for the main ones. The evolution of $\mathrm{CO}_{2}$ and $\mathrm{CO}$ concentrations are plotted respectively in Figure 4 and Figure 5 as a function of the initial temperature in the chamber. As presented previously, when the initial temperature is lower than $1500 \mathrm{~K}$, the concentration of $\mathrm{CO}$ and $\mathrm{CO}_{2}$ are not affected by the chemical equilibrium. When the initial temperature increases, the $\mathrm{CO}$ concentration increases as well, whereas to satisfy the $\mathrm{C}$ balance, the $\mathrm{CO}_{2}$ concentration decreases. For the different initial temperatures, the relative errors between CHEMKIN and our OD model are always under $2 \%$. For an initial temperature at 
TABLE 2

Comparison between CHEMKIN and the 0D Diesel Combustion model

\begin{tabular}{|c|c|c|c|c|c|c|}
\hline$\underline{T_{0}(\mathrm{~K})}$ & & 1500 & 2000 & 3000 & 4000 & 5000 \\
\hline \multirow[t]{3}{*}{ Pressure (bar) } & CHEMKIN & 49.098 & 49.64 & 46.19 & 42.32 & 39.62 \\
\hline & 0D Combustion model & 49.99 & 49.65 & 46.13 & 42.16 & 39.47 \\
\hline & Error $(\%)$ & -0.01 & -0.01 & 0.13 & 0.37 & 0.37 \\
\hline \multirow[t]{3}{*}{ Temperature $(\mathrm{K})$} & CHEMKIN & 1499.5 & 1982.9 & 2691.5 & 3108.6 & 3407.2 \\
\hline & 0D Combustion model & 1499.5 & 1982.8 & 2688.8 & 3100.7 & 3399.4 \\
\hline & Error $(\%)$ & 0.00 & 0.00 & 0.10 & 0.25 & 0.23 \\
\hline \multirow[t]{3}{*}{$X_{\mathrm{O} 2}$} & CHEMKIN & $3.776 \mathrm{E}-05$ & $1.302 \mathrm{E}-03$ & $2.190 \mathrm{E}-02$ & $5.525 \mathrm{E}-02$ & $8.260 \mathrm{E}-02$ \\
\hline & 0D Combustion model & $3.768 \mathrm{E}-05$ & $1.299 \mathrm{E}-03$ & $2.171 \mathrm{E}-02$ & $5.455 \mathrm{E}-02$ & $8.205 \mathrm{E}-02$ \\
\hline & Error $(\%)$ & 0.20 & 0.23 & 0.87 & 1.28 & 0.66 \\
\hline \multirow[t]{3}{*}{$X_{\mathrm{H} 2}$} & CHEMKIN & $2.048 \mathrm{E}-05$ & 4.703E-04 & $6.269 \mathrm{E}-03$ & $1.658 \mathrm{E}-02$ & $2.812 \mathrm{E}-02$ \\
\hline & 0D Combustion model & $2.054 \mathrm{E}-05$ & 4.735E-04 & $6.323 \mathrm{E}-03$ & $1.669 \mathrm{E}-02$ & $2.848 \mathrm{E}-02$ \\
\hline & Error $(\%)$ & -0.29 & -0.67 & -0.87 & -0.64 & -1.28 \\
\hline \multirow[t]{3}{*}{$X_{\mathrm{H} 2 \mathrm{O}}$} & CHEMKIN & 0.4738 & 0.4725 & 0.4478 & 0.3977 & 0.3395 \\
\hline & 0D Combustion model & 0.4739 & 0.4725 & 0.4480 & 0.3985 & 0.3402 \\
\hline & Error $(\%)$ & -0.01 & 0.00 & -0.04 & -0.20 & -0.21 \\
\hline \multirow[t]{3}{*}{$X_{\mathrm{OH}}$} & CHEMKIN & 7.378E-06 & 4.317E-04 & $1.161 \mathrm{E}-02$ & $3.720 \mathrm{E}-02$ & $6.678 \mathrm{E}-02$ \\
\hline & 0D Combustion model & 7.313E-06 & 4.298E-04 & 1.153E-02 & 3.672E-02 & $6.632 \mathrm{E}-02$ \\
\hline & Error (\%) & 0.87 & 0.44 & 0.71 & 1.30 & 0.69 \\
\hline \multirow[t]{3}{*}{$X_{\mathrm{O}}$} & CHEMKIN & 3.496E-09 & 2.997E-06 & 7.578E-04 & $5.856 \mathrm{E}-03$ & $1.768 \mathrm{E}-02$ \\
\hline & 0D Combustion model & $3.495 \mathrm{E}-09$ & $2.994 \mathrm{E}-06$ & 7.465E-04 & $5.685 \mathrm{E}-03$ & $1.730 \mathrm{E}-02$ \\
\hline & Error $(\%)$ & 0.04 & 0.09 & 1.49 & 2.92 & 2.17 \\
\hline \multirow[t]{3}{*}{$X_{\mathrm{H}}$} & CHEMKIN & 1.119E-08 & 4.450E-06 & $6.415 \mathrm{E}-04$ & 4.315E-03 & $1.268 \mathrm{E}-02$ \\
\hline & 0D Combustion model & $1.125 \mathrm{E}-08$ & 4.475E-06 & $6.395 \mathrm{E}-04$ & $4.250 \mathrm{E}-03$ & $1.258 \mathrm{E}-02$ \\
\hline & Error $(\%)$ & -0.52 & -0.57 & 0.32 & 1.52 & 0.81 \\
\hline \multirow[t]{3}{*}{$X_{\mathrm{CO} 2}$} & CHEMKIN & 0.5260 & 0.5229 & 0.4671 & 0.3666 & 0.2703 \\
\hline & 0D Combustion model & 0.5260 & $5.230 \mathrm{E}-01$ & 0.4678 & 0.3693 & 0.2733 \\
\hline & Error $(\%)$ & 0.00 & -0.01 & -0.15 & -0.74 & -1.11 \\
\hline \multirow[t]{3}{*}{$X_{C O}$} & CHEMKIN & $5.875 \mathrm{E}-05$ & $2.351 \mathrm{E}-03$ & 4.381E-02 & $1.164 \mathrm{E}-01$ & $1.821 \mathrm{E}-01$ \\
\hline & 0D Combustion model & $5.848 \mathrm{E}-05$ & $2.340 \mathrm{E}-03$ & 0.0433 & $1.143 \mathrm{E}-01$ & $1.798 \mathrm{E}-01$ \\
\hline & Error $(\%)$ & 0.45 & 0.46 & 1.20 & 1.78 & 1.27 \\
\hline
\end{tabular}

$1500 \mathrm{~K}$, the composition of the mixture and the thermodynamic conditions are not affected by the chemical equilibrium. In order to limit the CPU consumption of the $0 \mathrm{D}$ combustion model, it will be thus possible to limit the simulation of the chemical equilibrium for burnt gas temperatures higher than $1500 \mathrm{~K}$. When the initial temperature in the reactor increases, the impact of the chemical equilibrium on the composition, pressure and temperature increases also. For an initial temperature of $4000 \mathrm{~K}$ and an initial molar fraction of $\mathrm{CO}_{2}$ of 0.5261 , the final values of the temperature and the molar fraction of $\mathrm{CO}_{2}$ at the chemical equilibrium are $3100.7 \mathrm{~K}$ and 0.3693 respectively. For this range of temperature, the chemical equilibrium cannot be neglected and will influence the composition of the gases in the burnt gas zones.

\subsection{NO Formation}

The extended Zel'dovich mechanism for NO formation is presented in [19], and is commonly used in combustion models. The formation and destruction of NO is described with a system of 3 reversible Equations 13. 


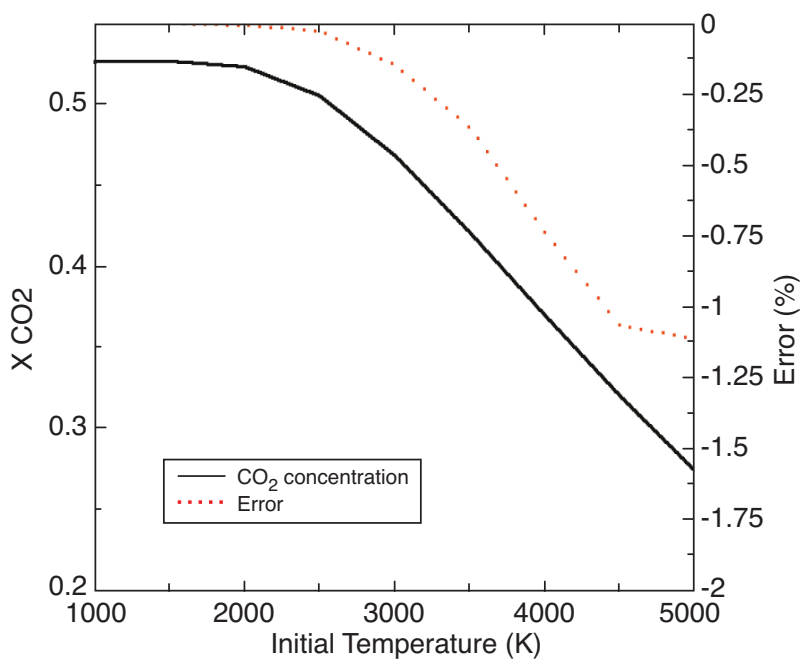

Figure 4

Evolution of $\mathrm{CO}_{2}$ concentration.

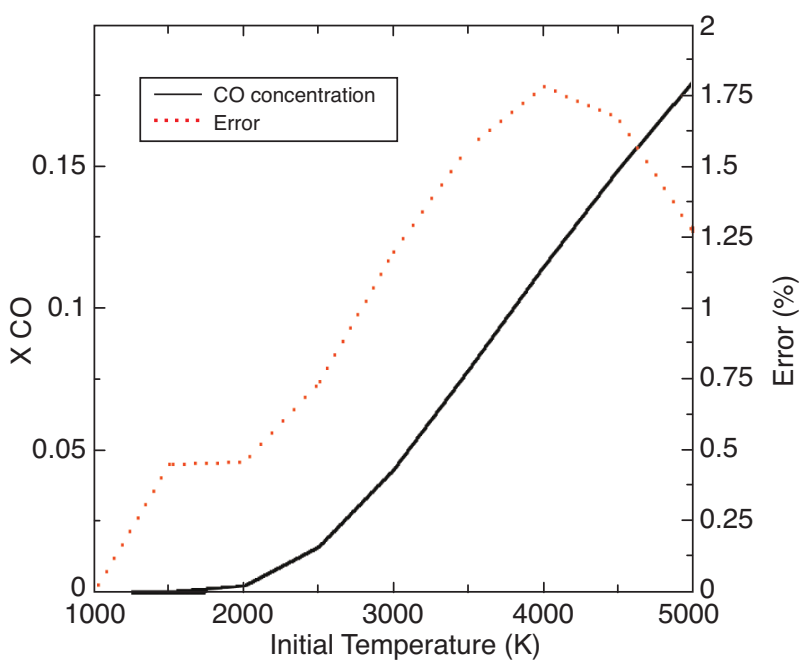

Figure 5

Evolution of $\mathrm{CO}$ concentration.

$$
\left\{\begin{array}{l}
N_{2}+O \leftrightarrow N O+N \\
O_{2}+N \leftrightarrow N O+O \\
O H+N \leftrightarrow H+N O
\end{array}\right.
$$

The system is solved using the kinetic constants $K_{i}$ of the different equations $i$, with an index + for the forward direction of the equation and - for the reverse one. The evolution of $\mathrm{NO}$ is then defined as:

$$
\begin{aligned}
\frac{d[N O]}{d t} & =K_{1}^{+}[O]\left[N_{2}\right]+K_{2}^{+}[N]\left[O_{2}\right]+K_{3}^{+}[N][O H] \\
& -K_{1}^{-}[N O][N]-K_{2}^{-}[N O][O]-K_{3}^{-}[N O][H]
\end{aligned}
$$

The kinetic constant $K_{i}$ is defined in Table 3 .

TABLE 3

Rate constant for NO formation mechanism

\begin{tabular}{c|l}
\hline Kinetic constant & \multicolumn{1}{|c}{ Rate constant, $\mathrm{cm}^{3} / \mathrm{mol} . \mathrm{s}$} \\
\hline$K_{1}^{+}$ & $7.6 \times 10^{13} \exp [-38000 / \mathrm{T}]$ \\
$K_{1}^{-}$ & $1.6 \times 10^{13}$ \\
\hline$K_{2}^{+}$ & $6.4 \times 10^{9} \mathrm{Texp}[-3150 / \mathrm{T}]$ \\
$K_{2}^{-}$ & $1.5 \times 10^{9} \mathrm{Texp}[-19500 / \mathrm{T}]$ \\
\hline$K_{3}^{-}$ & $4.1 \times 10^{13}$ \\
$K_{3}^{-}$ & $2.0 \times 10^{14} \exp [-23650 / \mathrm{T}]$ \\
\hline
\end{tabular}

where $T$ is the temperature $(\mathrm{K})$ in the burnt gas zone.

\section{INTEGRATION OF THE COMBUSTION MODEL IN THE ENGINE SIMULATION TOOL}

\subsection{General Description}

The Diesel combustion model is implemented in the AMESim Platform, using the IFP-Engine library. This library allows the simulation of complete virtual engines using a characteristic time scale of the order of the crankshaft angle. A variety of elements is available to build representative models for internal combustion engines such as pipes, valves, turbocharger, injector, combustion chambers... Figure 6 presents these components. Moreover, the library uses an advanced modelling approach to take account of the relevant physical phenomena that occur in an engine [2].

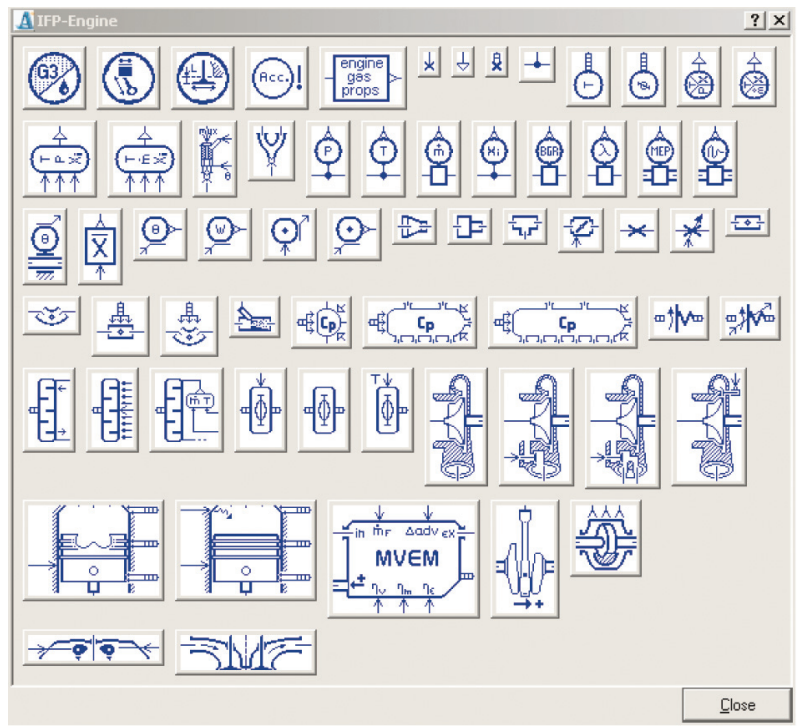

Figure 6

IFP-Engine library. 


\subsection{Coupling the Diesel Combustion Model with the Pollutant Formation Model}

As presented in the first part of the paper, the Diesel combustion model is able to define the combustion heat release rate according to the injected mass flow rate and the in-cylinder thermodynamic conditions. The next step of the development is to couple this combustion model to the pollutant formation model. The pollutant formation can not be computed in the average combustion chamber mixture, one of the main challenges is to create a burnt gas zone, in which chemical equilibrium and $\mathrm{NO}_{\mathrm{x}}$ formation could occur.

To define the burnt gas zone, one assumes that the pressure in the combustion chamber is homogeneous. The combustion heat release rate is also transferred to the burnt zone; the unburned (or fresh) zone is only affected by the compression and extension of the combustion chamber volume and by the heat exchange with the combustion chamber walls. The last variable required to compute the burnt zone thermodynamic properties is the evolution of the mass of the different species. In the burnt gases, the evolution of the mass of the species $i,\left.\frac{d m_{i}}{d t}\right|_{b g}$ is defined as:

$$
\left.\frac{d m_{i}}{d t}\right|_{b g}=\left.\frac{d m_{i}}{d t}\right|_{\text {comb }}+\left.\frac{d m_{i}}{d t}\right|_{f g \rightarrow b g}+\left.\frac{d m_{i}}{d t}\right|_{\text {chem_equil }}+\left.\frac{d m_{i}}{d t}\right|_{N O}
$$

where $\left.\frac{d m_{i}}{d t}\right|_{\text {comb }}$ is the mass flow rate of the specie $i$, according to the combustion process, presented in Equation 9. In a first step, the Fuel/Air equivalence ratio defined in the premixed zone can be used to compute the mass flow rate of the species involved in the combustion of the premixed zone, see Equation 9. During the diffusion mode of the combustion, the Fuel/Air equivalence ratio is not defined in the model and the use of the average Fuel/Air equivalence ratio does not seem relevant since it is not representative of the local Fuel/Air equivalence ratio at which combustion occurs. Generally, the diffusion combustion mode is supposed to occur in the slightly rich zone. Using 3D CFD results, the Fuel/Air equivalence ratio $\Phi$ for the diffusion combustion mode is set at 1.02 .

The terms $\left.\frac{d m_{i}}{d t}\right|_{\text {chem_equil }}$ and $\left.\frac{d m_{i}}{d t}\right|_{N O}$ are the mass flow rate created by the pollutant formation models. They are defined using System 11 for the chemical equilibrium and System 13 for the NO formation respectively. The last term $\left.\frac{d m_{i}}{d t}\right|_{f g \rightarrow b g}$ defines the entrained mass of fresh gases to the burnt ones. The entrained air in the burnt gases is a function of the turbulence induced by the spray. Using the simple turbulent model defined in [16], the turbulent kinetic energy $k$ and the turbulent dissipative kinetic energy $\varepsilon$ of the spray can be computed. It is then possible to define a mixing time $\tau$, as:

$$
\tau=\frac{k}{\varepsilon}
$$

The entrained mass of fresh gases to the burnt gases becomes:

$$
\left.\frac{d m_{i}}{d t}\right|_{f g \rightarrow b g}=\alpha \cdot \frac{m_{i, f g}}{\tau}
$$

where $\alpha$ is a parameter to fit the composition in the burnt gases and $m_{i, f g}$ is the mass of the species in the fresh gases. This parameter is defined as a function of the engine speed and the expected IMEP.

\section{ENGINE SIMULATION}

The validation of the 0D Diesel combustion and pollutant emissions models is conducted using a standard 4-cylinder turbocharged Diesel engine. The different steps of the validation are presented in this part, from the validation of the combustion model using a single cylinder simulator and the steady state experimental conditions, to the simulation of the associated 4-cylinders engine under transient evolution.

\subsection{Engine Set Up}

This paragraph aims to describe the engine hardware in terms of combustion chamber parts, compression ratio, turbocharger and type of EGR circuit, as presented in Figure 7.

The multi-cylinder application is based on the Renault G9T engine. Table 4 regroups the engine main characteristics.

TABLE 4

Engine main characteristics

\begin{tabular}{c|c}
\hline Bore $\times$ Stroke & $87.0 \times 92.0 \mathrm{~mm}$ \\
\hline Number of cylinders & 4 \\
\hline Displacement & 2.2 Litters \\
\hline Injection device & Solenoid \\
\hline Maximum injection pressure & 1600 bar \\
\hline Turbocharger & Variable Nozzle Turbine \\
\hline Valve timing & Original manufactured engine valve timing \\
\hline
\end{tabular}

As mentioned previously, the components of the combustion chamber were defined using single cylinder tests. The piston was designed with the NADI ${ }^{\mathrm{TM}}$ [26] bowl drawing specifications and the bowl volume was adapted to obtain a compression ratio of 14:1. The intake ducts of the cylinder head were modified in order to adapt the swirl motion to the 


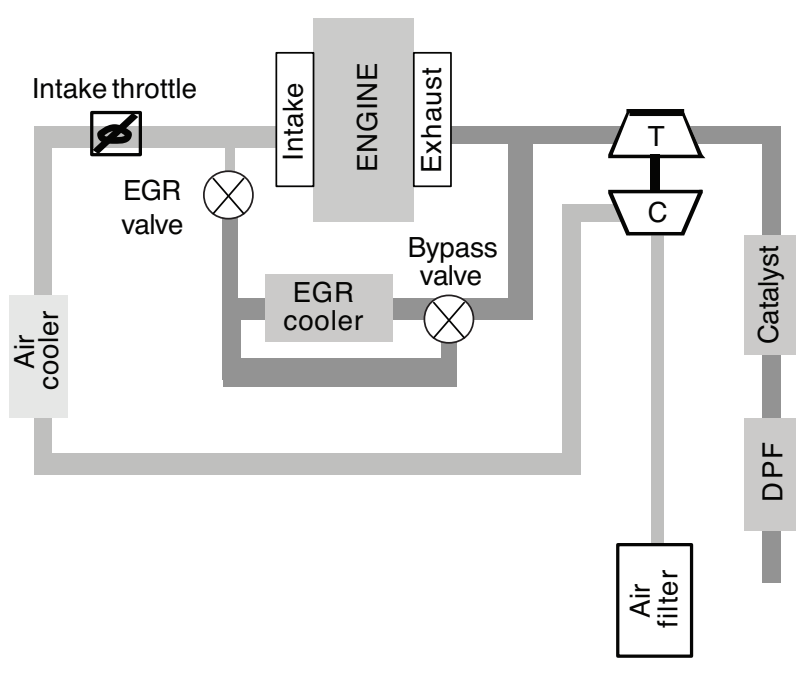

Figure 7

Engine architecture.

required swirl number of 1.3 at BDC. All the results shown in this paper, including full load conditions, were obtained with the same swirl number, without any inlet duct closure. The experimental test bed is fully described in [28] with the characteristic and position of the main pressure and temperature sensors.

The injection system works with a maximum injection pressure of 1600 bar. The features of the injectors used are defined in Table 5 .

The NADI ${ }^{\mathrm{TM}}$ application presented here is an engine equipped with only one turbocharger. The turbocharger was chosen in order to reach the power target fixed at full load. The turbocharger technology is conventional but the compressor and the turbine efficiency have been slightly improved compared to a production turbocharger. The air circuit includes an air cooler to maintain the temperature at $50^{\circ} \mathrm{C}$ in the intake manifold at full load.

TABLE 5

Injectors' main characteristics

\begin{tabular}{c|c}
\hline Spray cone angle & $60^{\circ}$ \\
\hline Number of holes & 6 \\
\hline Flow rate & $500 \mathrm{ml} / 30$ seconds $/ 100 \mathrm{bar}$ \\
\hline
\end{tabular}

A standard commercial Diesel fuel with less than $50 \mathrm{ppm}$ sulphur content has been used. The exhaust gas analysis is performed using a Horiba 7100 DEGR analyzer. It is connected to the exhaust line between the turbine and the exhaust catalyst. In this paper, we have mainly exploited the in-cylinder pressure, the temperature and pressure in the intake and exhaust manifolds, and the gas analysis in the exhaust line before the catalyst.

\subsection{Validation of the Combustion and Pollutant Models}

The validation and fitting of the OD Diesel combustion and pollutant emission models are made on a simple single cylinder architecture simulator (as presented in Fig. 8). Using this simulator, the combustion is isolated from the entire engine. The simulation is defined from intake valves closure (IVC) to exhaust valves opening (EVO). The initial in-cylinder thermodynamic conditions are defined using the experimental results for the steady state points. The advantage of this approach is to lower the error generated by the air path on the in-cylinder conditions at the IVC.

In order to optimize the fitting of the different parameters of the combustion and pollutant models on the experimental steady state points, we use an automatic calibration tool based on optimization algorithms, developed with softwares like Matlab or Scilab [27]. This tool is able to optimize constant or variable parameters in order to minimize errors on common variables as the IMEP or the pollutant emissions.

The validation of the combustion model was conducted for 2 engine speeds (1500 and $3000 \mathrm{rpm}$ ) and different IMEP. The different engine speed and IMEP for the selected points are plotted in Figure 9. The combustion model is then fitted on the experimental results (averaged pressure curve, and $\mathrm{CO}$ and NO emissions) using the automatic calibration tool; a constant set of parameters for the combustion model is defined
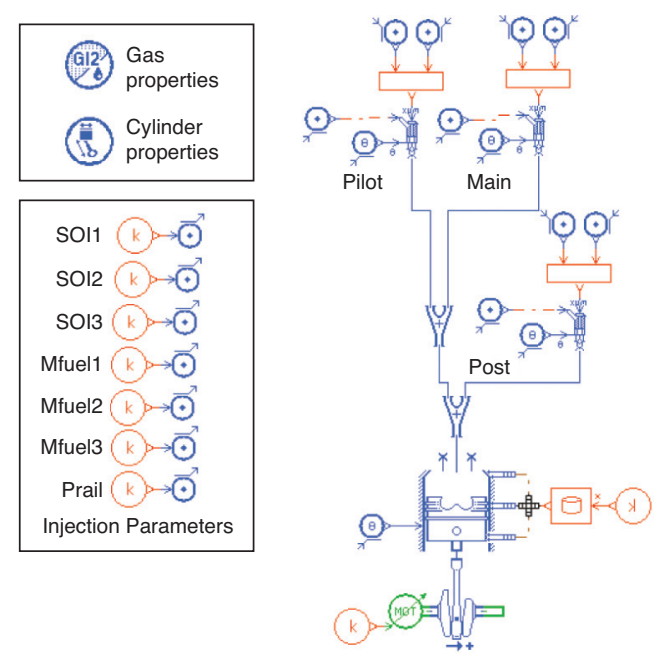

Figure 8

Single cylinder simulator. 


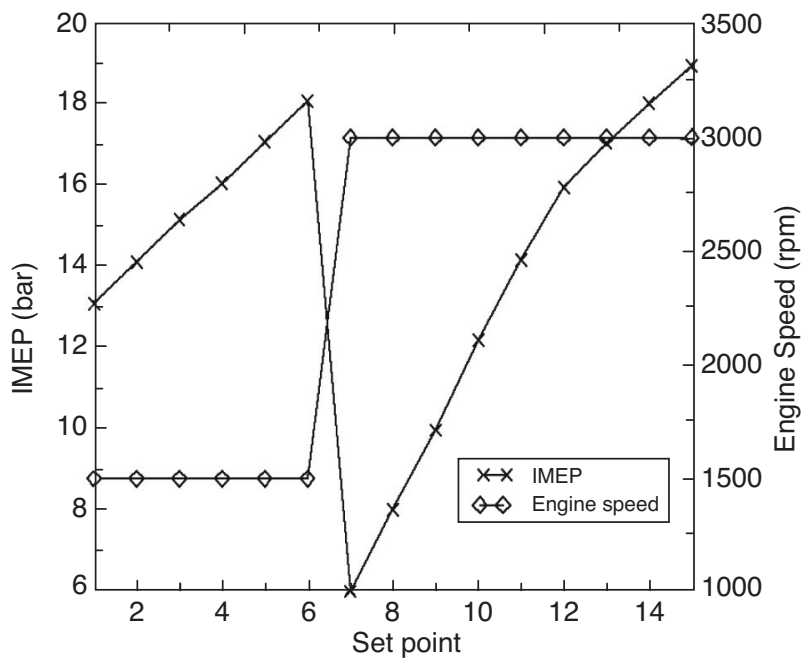

Figure 9

IMEP and engine speed of the 15 set points.

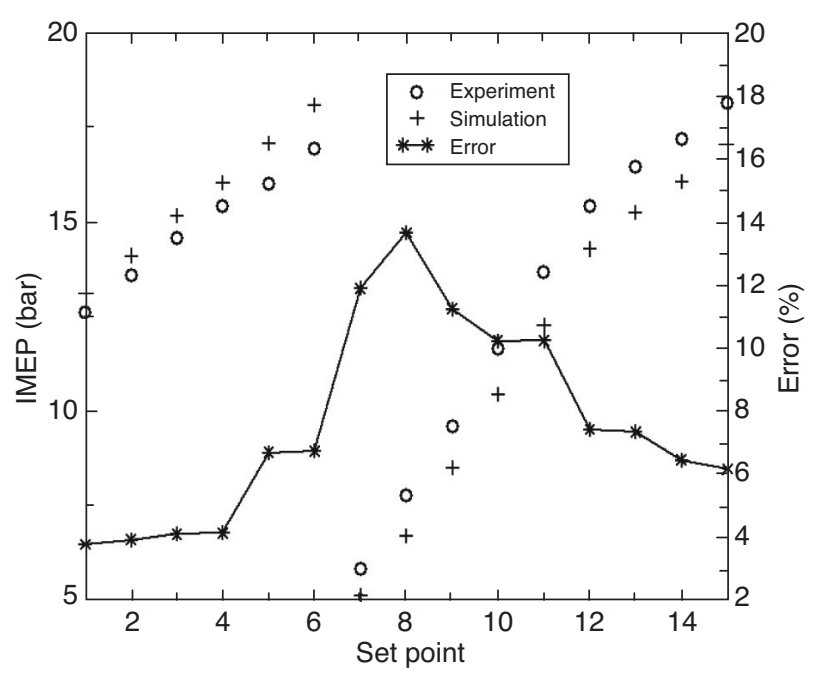

Figure 11

Experimental and simulated IMEP.

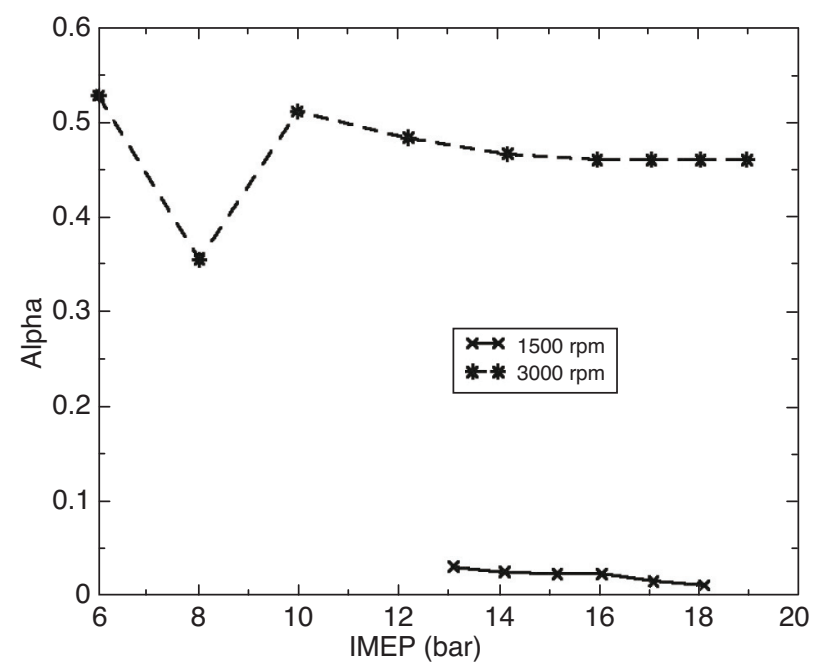

Figure 10

Evolution of the parameter as a function of the expected IMEP (bar).

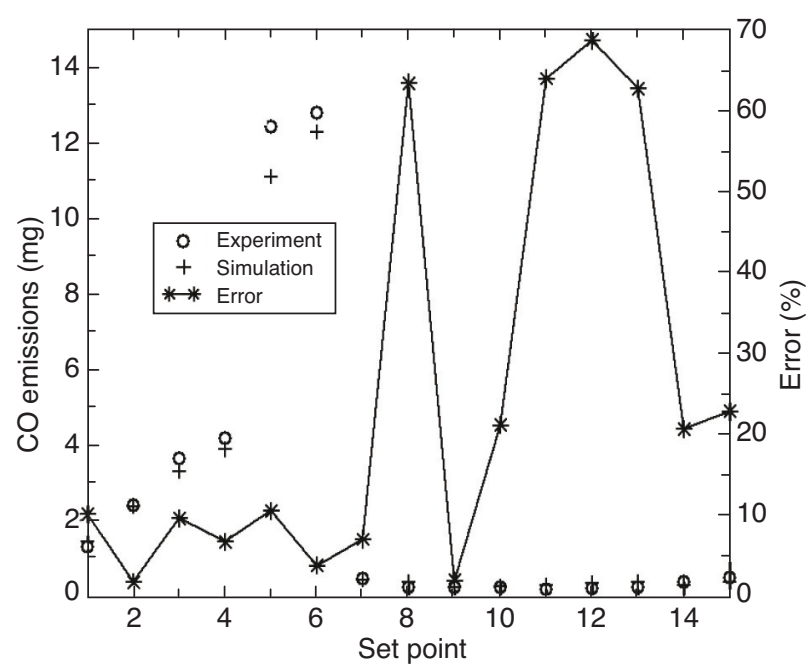

Figure 12

Experimental and simulated $\mathrm{CO}$ emissions. (excepted for $C_{g}$ which has 2 values) for all engine speeds. The parameter of the pollutant emissions model is calibrated to obtain a correct evolution of the $\mathrm{CO}$ and $\mathrm{NO}$ emissions. The constant parameters of the combustion and pollutant models obtained with the automatic calibration tool are grouped in Table 6 . The evolution of the parameter as a function of the engine speed and the expected IMEP is plotted in Figure 10.

The combustion model is calibrated with a constant set of parameters for the 15 experimental points. Figure 11Figure 13 present the comparison between experimental and simulated results for the evolution of the IMEP, CO and NO emissions. In the graphs, the dotted symbols represent the experimental results, the + the simulated ones and the solid line with stars is for the relative errors between experimental and simulated results. The evolution of the simulated IMEP is in good agreement with the experimental results. The relative error for the points at $1500 \mathrm{rpm}$ is under $6 \%$. For the points at $3000 \mathrm{rpm}$, the relative error is higher at low IMEP and decreases for higher IMEP. After calibration of the combustion model, the $\alpha$ parameter of the pollutant model is 


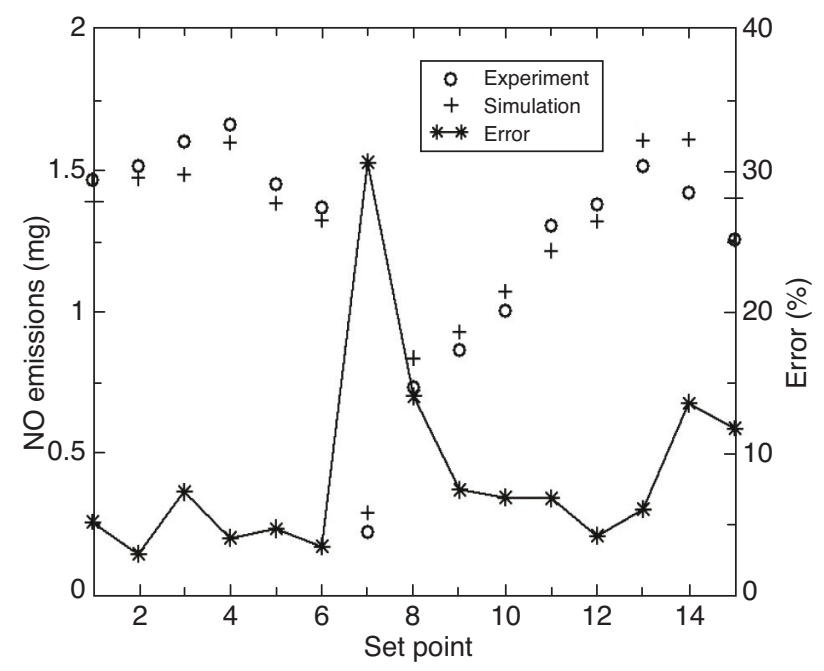

Figure 13

Experimental and simulated NO emissions.

TABLE 6

Optimized combustion and pollutant model constant parameters

\begin{tabular}{|c|c|c|c|}
\hline \multicolumn{4}{|c|}{ Auto-ignition delay parameters } \\
\hline \multirow{2}{*}{$A_{t}$} & \multicolumn{2}{|l|}{ 1st injection } & 0.09 \\
\hline & \multicolumn{2}{|l|}{ 2nd injection } & 0.035 \\
\hline \multirow{2}{*}{$n$} & \multicolumn{2}{|l|}{ 1st injection } & 2.09 \\
\hline & \multicolumn{2}{|l|}{ 2nd injection } & 1.35 \\
\hline \multirow{2}{*}{$T_{A}[\mathrm{~K}]$} & \multicolumn{2}{|l|}{ 1st injection } & 6126 \\
\hline & \multicolumn{2}{|l|}{ 2nd injection } & 7025 \\
\hline \multirow{2}{*}{$\gamma$} & \multicolumn{2}{|l|}{ 1st injection } & 2.97 \\
\hline & \multicolumn{2}{|l|}{ 2nd injection } & 1.20 \\
\hline \multicolumn{4}{|c|}{ Combustion model parameters } \\
\hline \multicolumn{2}{|c|}{ Spray turbulent kinetic energy creation } & \multicolumn{2}{|l|}{0.0038} \\
\hline \multicolumn{2}{|c|}{ Spray turbulent kinetic energy dissipation } & \multicolumn{2}{|l|}{0.046} \\
\hline \multicolumn{2}{|c|}{ Pre-mixed combustion parameter } & \multicolumn{2}{|l|}{2026} \\
\hline \multicolumn{2}{|c|}{$\begin{array}{l}\text { Parameter for the transition between } \\
\text { pre-mixed and diffusion combustion modes }\end{array}$} & \multicolumn{2}{|l|}{7.93} \\
\hline \multicolumn{2}{|l|}{$C_{k}$} & \multicolumn{2}{|l|}{0.027} \\
\hline \multicolumn{2}{|l|}{$C_{g}$} & \multicolumn{2}{|c|}{$\begin{array}{l}13.6 \text { (for } 1500 \mathrm{rpm}) \\
\text { and } 1.36 \text { (for } 3000 \mathrm{rpm})\end{array}$} \\
\hline \multicolumn{2}{|c|}{$\begin{array}{l}\text { Influence of exhaust gases of the diffusion } \\
\text { combustion mode }\end{array}$} & \multicolumn{2}{|l|}{0.069} \\
\hline
\end{tabular}

defined to fit the experimental $\mathrm{CO}$ and $\mathrm{NO}$ emissions. The results are plotted in Figure 12 and Figure 13. Compared with the experimental results, the predicted evolution of $\mathrm{CO}$ and $\mathrm{NO}$ emissions appear to reveal similar trends. For most of the cases, the relative error is under $10 \%$. When this error is higher than $10 \%$, the value of the pollutant emissions are low compared to other steady state points. In these cases, the pollutant formation model shows good agreement for the $\mathrm{CO}$ and $\mathrm{NO}$ emissions. For example, at $1500 \mathrm{rpm}$, the $\mathrm{CO}$ emissions are high and the pollutant model is in good agreement with the experimental results. For the experimental points at $3000 \mathrm{rpm}$, the $\mathrm{CO}$ emissions are negligible and the model can reproduce the fall of the $\mathrm{CO}$ emission, even with a high relative error. For these cases, the error generated by the experimental sensors is also significant and can be compared with the simulated results.

\subsection{Calibration of the Entire Engine Simulator}

The goal of engine system simulation is to supply the specific application with the relevant model. User expectations have to be accurately understood in order to achieve the optimum trade-off between physical description and calculation time cost. Engine control design has strong time cost constraints. It needs to perform a large amount of engine operating points and is oriented to real time environment. The reference engine model diagram is presented in Figure 14.

Air path includes a compressor, pipes, a heat exchanger, a throttle and an intake manifold. All these elements are represented by dedicated submodels. The combustion chamber is connected to the air path through the cylinder head which acts thanks to valve lift laws and permeability behaviour model derived from experimental characterization. The fuel injection system allows to perform up to three injections and to control each injection with the common rail pressure, the start of injection and the injection duration with an instantaneous injected fuel mass rate fitted on injector experimental data. In the cylinder, wall heat losses are modelled using a Woschni's approach with three independent temperatures for the cylinder head, the piston and the liner. The combustion heat release model has already been presented in the dedicated part.

The entire validation of the engine simulator had previously been performed for a wide range of operating points [28]. Using the new OD combustion and pollutant emissions models, it is possible to estimate the $\mathrm{CO}$ and $\mathrm{NO}$ emissions for the simulator.

\subsection{First Application on Transient Engine Simulation}

The use of a 0D combustion and pollutant emissions models is valuable to assess the in-cylinder pollutant emissions during an engine simulation. In-cylinder pollutant emissions are 


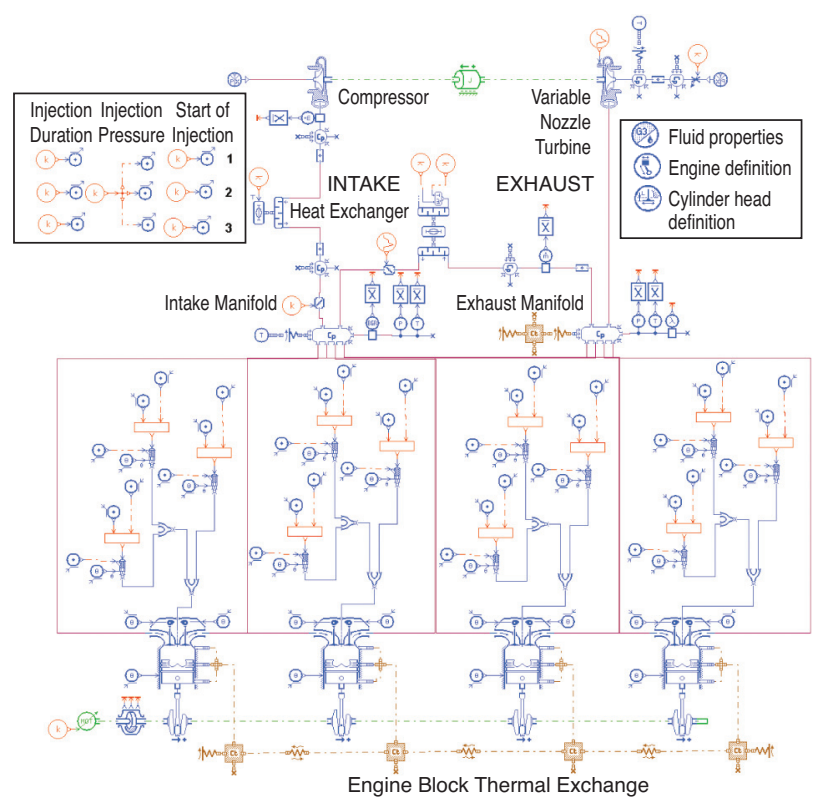

Figure 14

Diesel engine simulator.

generally defined using experimental tables generated with a large number of steady state points. The validity of this kind of approach is questionable since the pollutant emission tables are obtained for steady state points and not under transient evolution, and also because the input parameters of the tables are generally not directly connected to the in-cylinder thermodynamic conditions.

In this part, the opportunity to use the OD combustion and pollutant emissions models for a transient engine simulation is presented. Using the entire engine simulator described previously, the evolution of engine torque for a constant engine speed is simulated. In this part, the experimental engine is not used as it is difficult to estimate the transient $\mathrm{CO}$ and NO emissions. We decided to define a transient engine evolution without any engine control, using an open loop approach for the engine actuators. The actuators of the engine are defined at the beginning according to the first steady state point of Figure 9 (1500 rpm, $13 \mathrm{bar}$ ), then after 2 seconds, they are modified to represent the sixth one, on the same figure (1500 rpm, 18 bar). The evolution of the modelled engine IMEP is plotted in Figure 15. Until 2 seconds, the engine is stabilized around 11.5 bars, then according to the modification of the actuators, the IMEP increases to reach its new stabilized value.

The use of the system simulation allows the visualisation of valuable variables of the engine. For example, the intake and exhaust manifold pressures are presented in Figure 16 and Figure 17 respectively. One can see that the average value of the intake manifold pressure increases

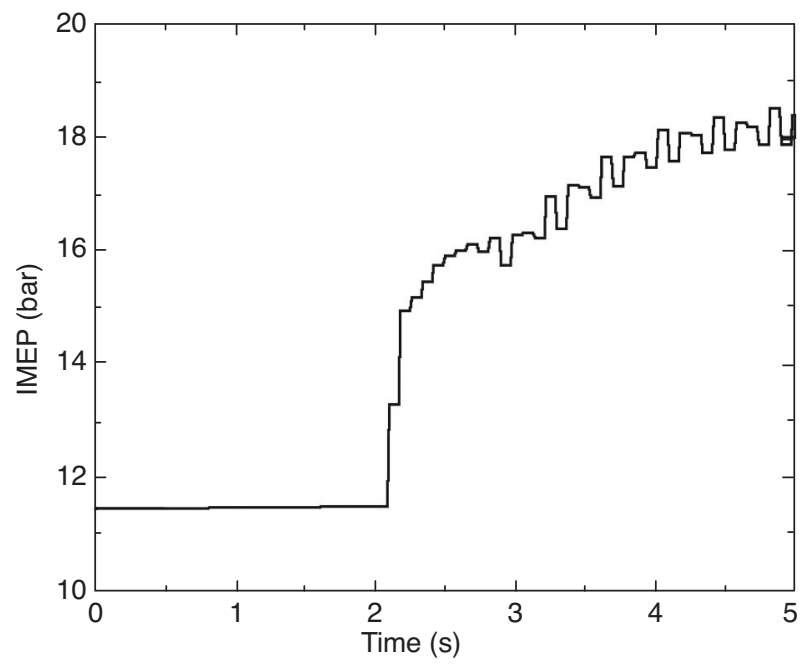

Figure 15

Evolution of the simulated IMEP during the transient engine simulation.

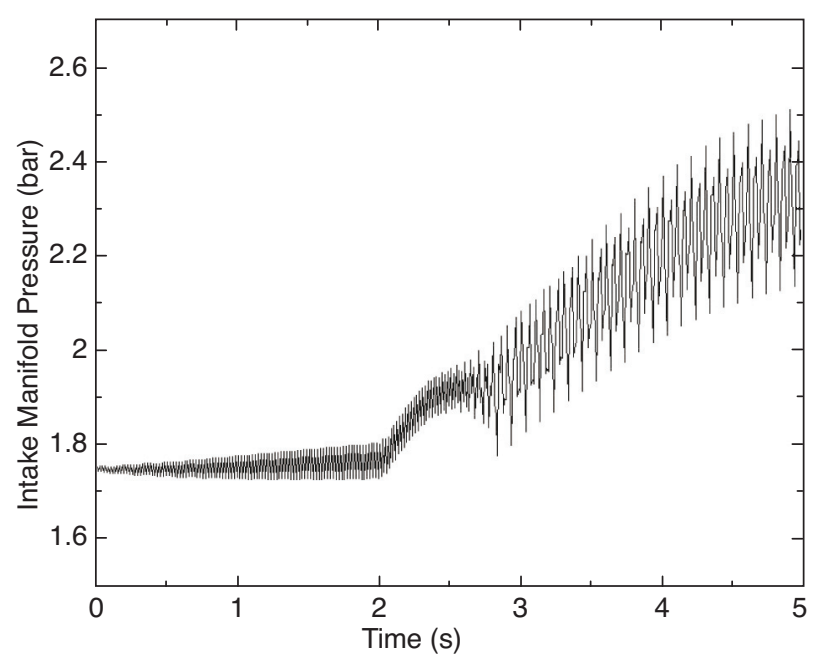

Figure 16

Evolution of the intake manifold pressure.

after 2 seconds, due to the modification of the engine actuator and the turbocharger influence. Moreover, the instantaneous exhaust mass flow rate for the $\mathrm{CO}$ and $\mathrm{NO}$ are represented in Figure 18 and Figure 19. These values are difficult to obtain experimentally and the system simulation represents an interesting way to assess them. During the transient engine simulation, the average exhaust $\mathrm{CO}$ and NO pollutant emissions vary but not in the same proportion. Besides, the $\mathrm{CO}$ and $\mathrm{NO}$ emissions evolve according to the in-cylinder thermodynamic conditions, thus after 4 seconds, their evolution is different: the $\mathrm{CO}$ emissions decrease and the NO remains constant. 


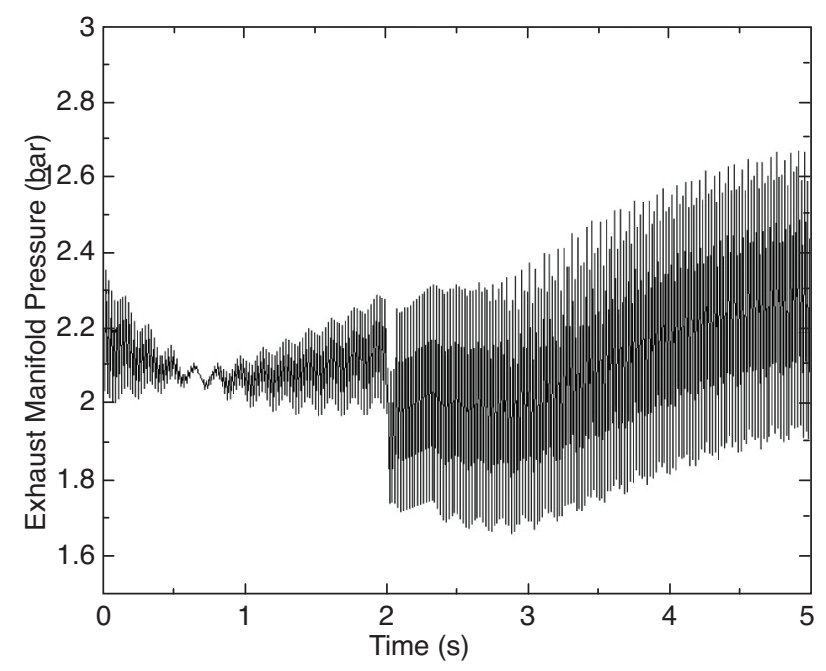

Figure 17

Evolution of the exhaust manifold pressure.

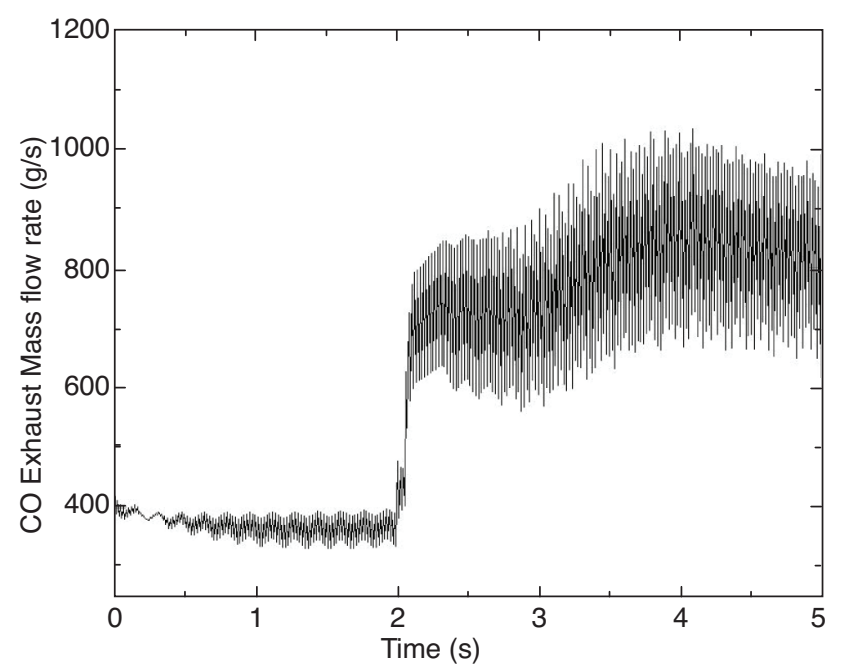

Figure 18

$\mathrm{CO}$ exhaust mass flow rate.

\section{CONCLUSION}

Engine system simulation appears to be a powerful tool for engine development and particularly for engine control development that require predictive models with low CPU consumption. In this paper, the development and validation of Diesel combustion and pollutant emission models are presented.

In a first step, using the available models in the literature, a promising combustion model is identified and adapted to our application. In a second step, this model is coupled to a pollutant formation model, to assess the $\mathrm{CO}$ and NO emissions during combustion. In the last part, this model is tested

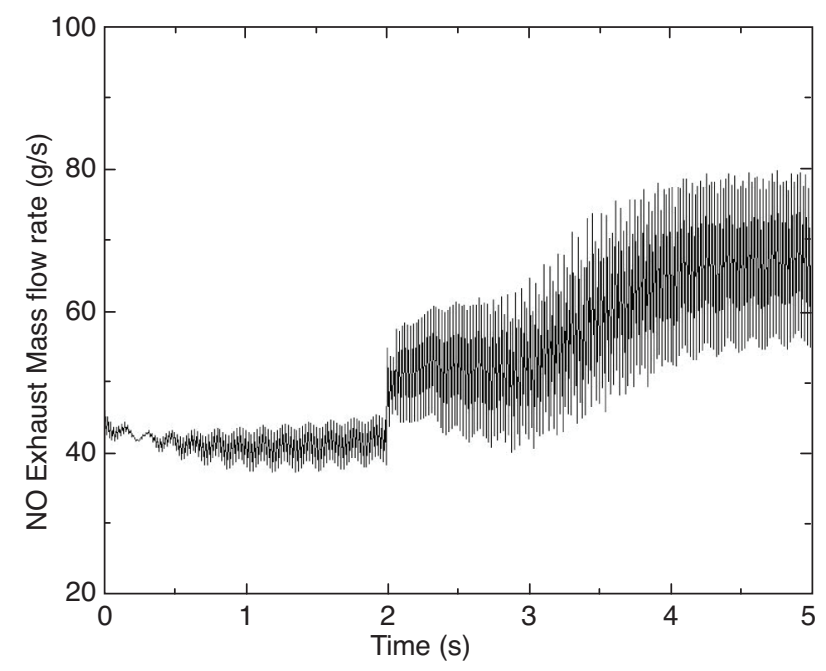

Figure 19

NO exhaust mass flow rate.

and validated with experimental results obtained on a 4 cylinder turbocharger DI Diesel engine. We show that the trends of the IMEP, CO and NO emissions for different steady state points are in good agreement with the experimental results, especially the $\mathrm{CO}$ emission drop when the engine speed increases. Finally, a simulation of a transient engine operation is computed to assess the interest to use the developed model in a complete engine simulator.

This paper represents a first step in the development of a predictive 0D Diesel combustion and pollutant emission model. In the future, the mixing model to create the burnt gas zone will be improved and tested on new experimental results in order to extend the predictivity of the approach. A simple soot formation and oxidation model will also be introduced to respond to engine control development needs. In parallel to these developments, more detailed Diesel combustion models are investigated in order to be able to reproduce the stratification of the Fuel/Air equivalence ratio in the combustion chamber and to introduce its impact on the autoignition delay and combustion behaviour [20].

\section{ACKNOWLEDGMENTS}

We would like to acknowledge the French Environment and Energy Management Agency (ADEME) and the French Ministère de la Recherche for supporting this work.

\section{REFERENCES}

1 Barba C., Burkhardt C., Boulouchos K., Bargende M. (2000) A phenomenological combustion model for heat release rate prediction in high speed DI Diesel engines with common rail injection, SAE Technical Paper 2000-01-2933. 
2 Menegazzi P., Aubret P., Badin F., Triguy R., Marchand C. (2006) An advanced simulation tool for the consumption, emissions, and performance analysis of conventional and hybrid vehicles, FISITA paper F2006P115, World Automotive Congress, Yokohama, 22-27 October 2006.

3 Colin O., Benkenida A. (2004) The 3-zones extended coherent flame model (ECFM3Z) for computing premixed/diffusion combustion, Oil Gas Sci. Technol. - Rev. IFP 59, 6, 593-609.

4 Reveillé B., Miche M., Jay S., Henriot S. (2004) Contribution of 3D CFD tools to the developement and understanding of Diesel engines: improving today's engines and designing tomorrow's power units, SIA Congress, Lyon, 2004.

5 Wiebe I.I. (1970) Brennverlauf und Kreisprozeb von Verbrennungsmotoren, VEB-Verlag Technik, Berlin.

6 Cesario N., Muscio C., Farina M., Amato P., Lavorgna M. (2004) Modelling the rate of heat release in common rail Diesel engines: a soft computing approach, SAE Technical Paper 200401-2967.

7 Bohbot J., Lafossas F.-A., Miche M., Chraibi M., Menegazzi P. (2004) A new coupling approach using a1D system simulation software and a 3D combustion code applied to transient engine operation, SAE Technical Paper 2004-01-3002.

8 Arsie I., Di Genova F., Pianese C., Rizzo G., Sorrentino M., Caraceni A., Cioffi P., Flauti G. (2003) A single-zone model for combustion and $\mathrm{NO}_{\mathrm{x}}$ simulation in common-rail multi-jet Diesel engines, SAE Technical Paper SAE_NA 2003-01-79.

9 Hiroyasu H., Kadota T., Arai M. (1983) Development and use of a spray combustion modelling to predict Diesel engine efficiency and pollutant emissions, Bull. JSME 26, 214.

10 Jung D., Assanis D.N. (2001) Multi-zone DI Diesel spray combustion model for cycle simulation studies of engine performance and emissions, SAE Technical Paper, 2001-01-1246.

11 Jaine T. (2004) Simulation zérodimensionnelle de la combustion dans un moteur Diesel à injection directe, Ph.D. Thesis, Université d'Orléans.

12 Shenghua L., Hwang J.W., Park J.K., Kim M.H., Chae J.O. (1999) Multizone model for DI Diesel engine combustion and emissions, SAE Technical Paper 1999-01-2926.

13 Asay R.J., Svensson K.I., Tree D.R. (2004) An empirical, mixing-limited, zero-dimensional model for Diesel combustion, $S A E$ Technical Paper 2004-01-0924.

14 Dec J.E. (1997) A conceptual model of DI Diesel combustion based on laser-sheet imaging", SAE Technical Paper 970873.

15 Bruneaux G., Augé M., Lemenand C. (2004) A study of Combustion structure in high pressure single hole common rail direct diesel injection using laser induced fluorescence of radicals, COMODIA Congress, Yokohama, 2004.

16 Chmela F.G., Orthaber G.C. (1999) Rate of heat prediction for direct injection Diesel engines based on purely mixing controlled combustion, SAE Technical Paper 1999-01-0186.
17 Chmela F., Engelmayer M., Pirker G., Wimmer A. (2004) Prediction of turbulence controlled combustion in Diesel engines, THIESEL 2004 conference on thermo and fluid dynamic processes in Diesel engines.

18 Schihl P., Tasdemir J., Schwarz E., Bryzik W. (2002) Development of a zero-dimensional heat release model for application to small bore Diesel engines, SAE Technical Paper 200201-0073.

19 Heywood J.B. (1988) Internal Combustion Engine Fundamentals, McGraw-Hill, New York.

20 Mauviot G., Albrecht A., Poinsot T.J. (2006) A New 0D approach for diesel combustion modelling coupling probability density function with complex chemistry, SAE Technical Paper 2006-01-3332.

21 Weisser G., Boulouchos L. (1995) NOEMI - A tool for the precalculation of Nitric Oxide emissions od DI Diesel engines, Technical University Graz.

22 Hountalas D.T., Kouremenos D.A., Pariotis E.G., (2002) Using a phenomenological multi-zone model to investigate the effect of injection rate shapping on performance and polluants of a DI heavy duty Diesel Engine, SAE Technical Paper 2002-01-0074.

23 Kouremenos D.A., Rakopoulos C.D., Hountalas D.T. (1997) Multi-zone combustion modelling for the prediction of pollutants emissions and performances of DI Diesel Engines, $S A E$ Technical Paper 970635.

24 Rakopoulos C.D., Rakopoulos D.C., Giakoumis E.G., Kyritsis D.C. (2003) Validation and sensitivity analysis of a two zone Diesel engine model for combustion and emissions prediction, Energ. Convers. Manage. 45, 1471-1495.

25 Torkzadeh D.D., Längst W., Kiencke U. (2001) Combustion and exhaust gas modeling of a common rail diesel engine - an Approach, SAE Technical Paper 2001-01-1243.

26 Walter B., Gatellier B. (2002) Development of the high power $\mathrm{NADI}^{\mathrm{TM}}$ concept using dual mode Diesel combustion to achieve zero $\mathrm{NO}_{\mathrm{x}}$ and particulate emissions, SAE Technical Paper 2002$01-1744$.

27 Miche M., Lafossas F.-A., Guillemin J., Enhanced phenomenological modelling of conventional and HCCI Diesel combustion using optimization algorithms for automatic calibration, ICE congress, Capri, Italy, 2007, to be published.

28 Albrecht A., Chauvin J., Lafossas F.-A., Potteau S., Corde G. (2006) Development of highly premixed combustion diesel engine model: from simulation to control design, SAE Technical Paper 2006-01-1072.

Final manuscript received in March 2008 Published online in August 2008 